\title{
CHAIN EXTENSION OF POLYAMIDE 6-ORGANOCLAY NANOCOMPOSITES
}

\author{
B. Tuna and H. Benkreira ${ }^{1}$
}

\author{
School of Engineering, R\&KT Centre in Advanced Materials Engineering \\ University of Bradford, BD7 1DP, UK
}

\begin{abstract}
Thermal degradation of PA6-organoclay nanocomposites is a serious impediment to wider applications of these nanocomposites. In this study, a solution is proposed, based on the well-established use of chain extenders. As in PA6, thermal degradation, in the absence of moisture, produces broken polymer chains with amide end groups, a chain extender with anhydride functionalities, known to be strongly reactive with amide groups, was used to reconnect the chains. Experiments conducted on a laboratory twin extruder were first checked, through TEM observations, to have produced good organoclay intercalation and exfoliation into the PA6. Following from this, samples with the chain extender added were produced and characterized. The data obtained were conclusive in the effectiveness of the chain extender: for the chain extended nanocomposite an enhancement of 7 times of the value of the complex viscosity and 88 times of the storage modulus whilst the tensile modulus increased by $57 \%$, compared with the neat PA6. The non-chain extended nanocomposite achieved in comparison an enhancement of 2 times the value of the complex viscosity, 19 times of the storage modulus whilst the tensile modulus increased by 53\%, compared to the neat PA6. These data provide conclusive proof on the rationale that anhydride functionalities should be sought when developing chain extenders for PA6 nanocomposites.
\end{abstract}

\section{INTRODUCTION}

In recent years, polymer nanocomposites have attracted much interest from both academia and industry due to their potential for a significant enhancement of properties such as mechanical, barrier and fire retardancy compared to the base virgin polymers. This properties enhancement is the result of the very large surface area provided by the nanoadditives for interaction with the polymer chains. Typically a nano additive is one nanometer thick, several hundred nanometers long and provides, at very small concentration $(<5 \%)$, a very large interfacial area in excess of $750 \mathrm{~m}^{2} / \mathrm{g}$ when fully dispersed in a polymer matrix. In practice however, the complete dispersion of nano additives within a polymer matrix, whether through in situ polymerisation, solvent blending or melt processing, is challenging and therefore limits a wider use of nanocomposites. The essential problem is one of dispersing a very small amount of stacks of nanoparticles held together in agglomerates into single nano particles and distributing these uniformly into a viscous mass of polymer. Without complete mixing, intercalation or the insertion of the polymer chains between the nano additive interlayers and exfoliation or delamination of the layered structures cannot be achieved and the benefits of the addition of the nano- additive is not attained. How dispersion was achieved formed an important aspect of the research and is explained in the Experimental Method section.

Amongst the nano additives, montmorillonite nanoclays are commonly preferred as they are a natural mineral, widely available and relatively cheap. They are layered silicates with hydrophilic inorganic cations on their surfaces [1]. To make them miscible with polymers, they require modification, usually by cation exchange with quaternary ammonium salts which

${ }^{1}$ Corresponding author e-mail address: H.Benkreira@bradford.ac.uk 
enlarge both the silicate inter gallery space and exchange hydrophilic groups with organophilic groups [2]. The resulting alkyl ammonium organoclays however undergo thermal degradation during melt extrusion above $200{ }^{\circ} \mathrm{C}$, forming $\alpha$-olefins and amines following Hofmann's elimination mechanisms [3], limiting the degree of intercalation and exfoliation as well as reducing molecular weight, thus the extent of properties enhancement.

There are two approaches to overcome thermal degradation, solid state polymerisation (SSP) and chain extension. With SSP, the treatment is after the event that is the degraded polymer is rebuilt by heating it just below its melt temperature for a period of time under vacuum or in an inert gas atmosphere. Clearly, this not only adds complexity to processing and an element of safety risk but also a high cost, making SSP unpopular in industry. Chain extension is a treatment during extrusion and works on the basis of adding an appropriate chemical (fed together with the polymer) that re-ties broken polymer chains as they form thus rebuilding molecular weight. As the amount of chain extender to be added is very small $(\sim 1-$ $3 \%)$, this solution is commonly sought in industry and has achieved much success with a range of polymers [4-6]. Whether, it can be applied to nanocomposites is less well established. This forms precisely the subject of this study on an important polymer nanocomposite, nylon (PA6)/nanoclay polymer nanocomposite, a land mark in polymer nanocomposite research, pioneered by Toyata [7].

Evidence of thermal degradation of PA6/organoclay nanocomposites can be found in various works; in one pass melt extrusion at $240{ }^{\circ} \mathrm{C}$ [8], in repeated melt extrusion below 240 ${ }^{\circ} \mathrm{C}$ [9] and in situ polymerisation at $300{ }^{\circ} \mathrm{C}$ [10]. Studies on the use of chain extenders to remedy thermal degradation of polymer nanocomposites are limited. Najafi et al. [11, 12] investigated the control of thermal degradation of polylactic acid /organoclay nanocomposites during twinscrew extrusion using three different chain extenders: polycarbodiimide, tris(nonyl phenyl) phosphite and an epoxy based multifunctional chain extender. On the basis of the rheological data measured, the epoxy based chain extender was found to be the most efficient. The same epoxy based multifunctional chain extender was found by Ghanbari et al. [13] to offset thermal degradation of polyethylene terephthalate (PET)/organoclay nanocomposites in twin-screw extrusion.

To the best of our knowledge, no report has been published on the control of thermal degradation of PA6/organoclay nanocomposites during melt extrusion using chain extenders, hence the importance of the present work. As inferred from the work of Najafi et al. [11, 12], the key to whether a chain extender is most appropriate or not is the potential of its functional group(s) (functionalities) to react with the end groups of the broken polymer chains and in doing form bonds that recouple the polymer chains. With PA6, assuming a non-moisture based degradation reaction, chain scission must occur on the thermally weakest bond, the alkyl-amide linkage [14] making the amide CONH groups the reconnecting links the proposed chain extender must target as illustrated in Fig. 1.

Now, anhydride functionalities are known to be strongly reactive with amide functionalities, forming stable imide bonds as shown in Fig.1, thus a good choice is a chain extender with multi-anhydride functionalities. This requirement is found in Joncryl ${ }^{\circledR}$ ADR 3400, a styrene maleic anhydride copolymer with repeated anhydride groups (see structure in Fig. 1) which we have tested successfully in previous study with recycled PA6 [15].

Another important consideration is the possibility of branching reactions occurring upon chain extension with Joncryl which will affect the processing and flow properties. This aspect is discussed in the Results and Discussion section. 


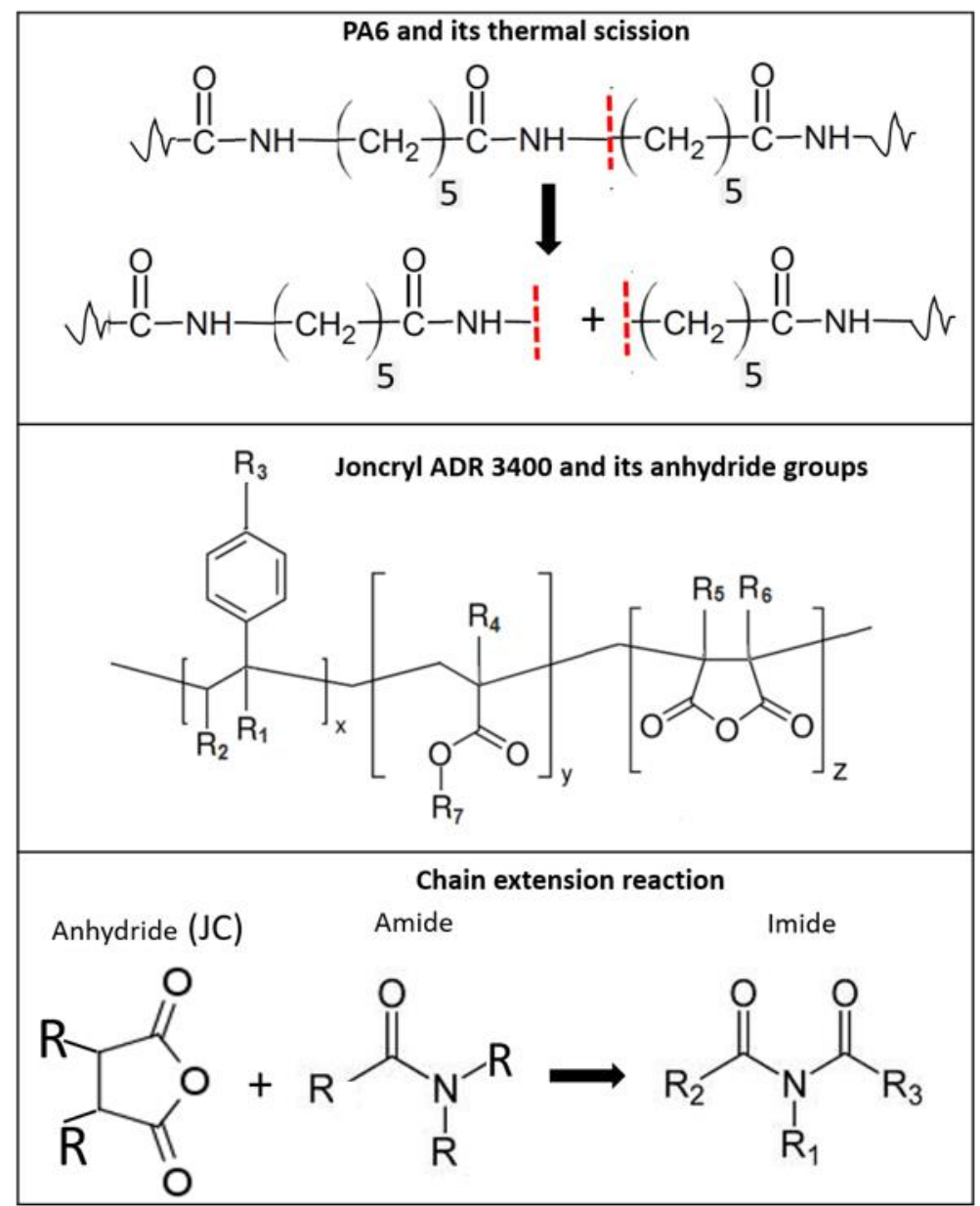

Fig. 1: Reaction mechanism and chemical structure of Joncryl 3400. R1-R6 are H, CH 3, a higher alkyl group or combinations of them; R7 is an alkyl group and $\mathrm{x}, \mathrm{y}$ and $\mathrm{z}$ are all between 1 and 20 .

\section{EXPERIMENTAL METHOD}

\subsection{Materials}

An extrusion grade PA6 (Akulon F-136) was purchased from DSM (Netherlands). It has a density of $1130 \mathrm{~kg} / \mathrm{m}^{3}$ and a melting point of $235^{\circ} \mathrm{C}$. As organoclay, Cloisite $30 \mathrm{~B}$ (Southern Clay Products Inc.) known from previous studies [16-18] to be readily exfoliated was used. Cloisite 30B is an organo-modified montmorillonite having two hydroxyl groups that react during extrusion with the carboxyl groups of PA6 to produce PA6/clay nanocomposites. It has a density of $1980 \mathrm{~kg} / \mathrm{m}^{3}$, a cation exchange capacity of $0.90 \mathrm{meq} / \mathrm{g}$ clay and a large specific surface $\left(970 \mathrm{~m}^{2} / \mathrm{g}\right)$ that offers strong interfacial interaction with the polymer matrix [19]. The chain extender of this study, Joncryl ${ }^{\circledR}$ ADR 3400 (Joncryl) in granular form, was supplied by BASF. It has a density of $600 \mathrm{~kg} / \mathrm{m}^{3}$ at $25^{\circ} \mathrm{C}$, a molecular weight of $10,000 \mathrm{~g} / \mathrm{mol}$ and a glass transition temperature $\left(\mathrm{T}_{\mathrm{g}}\right)$ of $133{ }^{\circ} \mathrm{C}$. As shown in Fig. 1, Joncryl ${ }^{\circledR}$ ADR 3400 is a styrene/acrylic copolymer which includes maleic anhydride in its structure making anhydride groups available for reaction. As discussed earlier, during chain extension the amine end groups of PA6 react with anhydride groups to form stable imide bonds.

\subsection{Extrusion}


As mentioned earlier, good dispersion of the polymer, nanoclay and chain extender was the first requirement of this work. To that effect, three compounders were first trialled [20], the Haake Minilab Micro Compounder (Thermo Fischer Scientific), the Xplore $15 \mathrm{ml}$ Micro Compounder and Bradford University Mini Mixer [21], before opting for a $19 \mathrm{~mm}(\mathrm{~L} / \mathrm{D}=28)$ co-rotating twin extruder from Baker Perkins (APV MP19TC). This extruder was configured with six zones (conveying - mixing - conveying - mixing - conveying - high shear pumping) with screws in the mixing zones fitted with angled paddles $\left(30^{\circ}, 60^{\circ}\right.$ and $\left.90^{\circ}\right)$ to ensure dispersive mixing following the distributive mixing created by the high shear conveying zones. Also, and in order to feed accurate amount of the PA6, nanoclay and chain extender into the extruder, each material was fed simultaneously and directly into the compounding screws using three separate screw feeders. Prior to extrusion, the PA6 pellets and chain extender powder were dried in a vacuum oven at $80{ }^{\circ} \mathrm{C}$ for 12 hours. The organoclay was dried at the higher temperature of $110{ }^{\circ} \mathrm{C}$ for 12 hours as recommended by the suppliers. The extruder was operated with a temperature profile set in the six zones from the hopper to the die at $230{ }^{\circ} \mathrm{C}$, $260{ }^{\circ} \mathrm{C}, 260{ }^{\circ} \mathrm{C}, 260{ }^{\circ} \mathrm{C}, 260{ }^{\circ} \mathrm{C}$ and $260{ }^{\circ} \mathrm{C}$, respectively. The extrusion was conducted at 100 rpm screw speed, producing $2.25 \mathrm{~kg} / \mathrm{hr}$ of a continuous $3 \mathrm{~mm}$ diameter strand, water cooled immediately on exit in a $1.5 \mathrm{~m}$ long trough and then pelletized. The polymer and polymer nanocomposite pellets were dried in a vacuum oven at $80{ }^{\circ} \mathrm{C}$ for 12 hours and then used for morphological, rheological, mechanical and thermal characterization.

\subsection{Characterization}

Transmission electron microscopy (TEM) was used to assess the morphology of the nanocomposites and the effect of the chain extender on the dispersion of the nanoclay in the PA6 matrix. Microtome sections were cryogenically cut with a diamond polymer knife at a temperature of $-100{ }^{\circ} \mathrm{C}$ using a LEICA EM UC6 Ultra-Microtome for viewing in a FEI TECNAI F30 TEM.

Rheological measurements were carried out using a Malvern Bohlin CVO120 rheometer. A parallel plate geometry was used with a gap size of $1 \mathrm{~mm}$ and a plate diameter of $25 \mathrm{~mm}$. First, time sweep tests were performed to determine the thermal stability of the samples over time. The tests were carried out at $1 \mathrm{~Hz}$ frequency over $1000 \mathrm{~s}$ at the extrusion temperature of 260 ${ }^{\circ} \mathrm{C}$. Frequency sweep tests were then conducted across a frequency range of 0.1 to $100 \mathrm{~Hz}$ at $0.1 \%$ strain, which was obtained from amplitude sweep tests to determine the linear viscoelastic region. The contribution of thermal degradation during frequency sweep tests was less than 5\% and considered to be negligible. Three samples were tested for each measurement and the results were found to be repeatable within a $0.2-5.7 \%$ error. For each experiment, a new sample was used.

Differential Scanning Calorimetry (DSC) measurements were performed using a Discovery DSC from TA Instruments. The samples, no more than $10 \mathrm{mg}$, standard aluminum pans and lids were carefully weighted using a precision balance, then the samples encapsulated. The experiments were carried out in heat-cool-heat cycles $\left(25^{\circ} \mathrm{C} \rightarrow 260{ }^{\circ} \mathrm{C} \rightarrow 25{ }^{\circ} \mathrm{C} \rightarrow 260{ }^{\circ} \mathrm{C}\right)$ at $10^{\circ} \mathrm{C} / \mathrm{min}$ under nitrogen purge at a flow rate of $50 \mathrm{~mL} / \mathrm{min}$. The degree of crystallinity of the samples was calculated using the standard equation:

$$
\chi_{c}=\frac{\Delta H_{m}}{w \Delta H_{m}^{0}}
$$

Here $\chi_{c}$ represents the degree of crystallinity, $w$ the weight fraction of PA6, $\Delta H_{m}$ the enthalpy of fusion of the samples and $\Delta H_{m}^{0}$ the enthalpy of fusion of $100 \%$ crystalline PA6 taken to be equal to $240 \mathrm{~J} / \mathrm{g}$ [22]. To erase thermal history, the second heating run was used to determine $\mathrm{T}_{\mathrm{g}}, \mathrm{T}_{\mathrm{m}}$ and $\Delta H_{\mathrm{m}}$. 
In an effort to provide evidence that the chain extension reaction is that between the amine end groups of PA6 and the anhydride groups of Joncryl to form stable imide bonds, infrared spectroscopy of the compounds (PA6, Joncryl and PA6/Joncryl) was carried out using a Nicolet iS50 FTIR Spectrometer (Thermo Fischer Scientific) in attenuated total reflectance mode at a resolution of $2 \mathrm{~cm}^{-1}$ and with 32 scans in a wavelength range of $600-4000 \mathrm{~cm}^{-1}$.

The degradation and thermal decomposition of the samples were studied using a Discovery TGA from TA Instruments. Samples, weighting approximately $10 \mathrm{mg}$, were tested in the temperature range $25^{\circ} \mathrm{C}$ to $600{ }^{\circ} \mathrm{C}$, at a heating rate of $10{ }^{\circ} \mathrm{C} / \mathrm{min}$ and purged with nitrogen at a flow rate of $50 \mathrm{~mL} / \mathrm{min}$.

The mechanical properties of the extruded samples were measured at ambient conditions with a $20 \mathrm{kN}$ tensile machine (Messphysik Beta) at a cross-head speed of $5 \mathrm{~mm} / \mathrm{min}$ with the strain measured on dumbbell shaped testing specimens according to ISO 37/4 test standard (middle section $12 \mathrm{~mm}$ long $\times 2 \mathrm{~mm}$ wide $\times 0.80 \mathrm{~mm}$ thick) using a video extensometer. The specimens were obtained by first moulding samples at $240{ }^{\circ} \mathrm{C}$ in a hydraulic press (Moore Ltd, UK) under $300 \mathrm{MPa}$ for $2 \mathrm{~min}$. After cooling to $30{ }^{\circ} \mathrm{C}$, the molded samples were cut into the dumbbell shape using a Metaserv Instrument. At least five samples were tested and average results with standard deviations were taken for each.

\section{RESULTS AND DISCUSSION}

Results are presented for the neat polymer (PA6), the chain extended polymer at $1 \%$ addition (PA6/1 JC), the polymer nanocomposite at 5\% organoclay addition (PA6/ 5 C30B) and the chain extended nanocomposite at $1 \%$ addition of chain extender and $5 \%$ addition of organoclay (PA6/1 JC/5 C30B).

\subsection{Morphology}

Images of the morphological observations of the nanocomposites with and without the chain extender are shown in Fig. 2, arranged from low to high magnification, with the dark lines corresponding to the clay layers. For the nanocomposites without Joncryl (Figs. 2a and c), exfoliated silicate layers and a few intercalated tactoids are observed in both sets of images suggesting that the reaction between hydroxyl groups of the clay and carboxyl groups of the PA6 had promoted dispersion of the clay. Addition of Joncryl to nanocomposites (Fig. 2b and d) increased the clay dispersion leading to a mainly exfoliated structure as a result of the strong shear force by the higher molecular weight matrix during extrusion. In the case of Joncryl, the nanocomposite transferred more stress to achieve separation of platelets due to its higher melt viscosity as will be establishedin the Rheology section below. Such influence of chain extenders on the dispersion of organoclay was previously reported in the literature $[12,13]$. The images of the nanocomposites containing Joncryl showed the alignment of the clay which was also observed in the study by Ghanbari et al. [13] for PET/organoclay nanocomposites containing a chain extender. This alignement can be attributed to flow orientiation during extrusion due to the higher viscosity matrix in the presence of Joncryl.

\subsection{Rheology}

Fig. 3, displaying time sweep data, assesses the thermal stability of the samples over time, showing the complex viscosity reducing over time for both the neat PA6 and PA6/5 C30B. The reduction behavior is more significant for PA6/5 C30B due to the accelerated thermal degradation effect of the organomodifier on the clay under high temperature and shear during the rheological tests. Although thermal instability of PA6/5 C30B was observed over time, it can be seen that, in comparison with the neat PA6, incorporation of organoclay into the PA6 matrix increased the magnitude of the complex viscosity due to polymer-filler interactions. 
For PA6/1 JC, that is for the non-nanocomposite chain extended case, it is evident that the chain extender had a significant effect on the control of thermal degradation of PA6 over time. Moreover, the addition of Joncryl led to an increase in the magnitude of viscosity which suggests a molecular weight increase. An interesting observation with PA6/1 JC is the increasing trend of the complex viscosity over time. Similar observations have been reported for multifunctional chain extender-polymer systems $[12,23]$. This behavior can be explained here by an on-going chain extension reaction in the rheometer between the anhydride groups of Joncryl and the amine end groups of PA6. In the extrusion experiments, the residence time is short (ca. $1 \mathrm{~min}$ ) and not sufficient to complete the chain extension reaction.
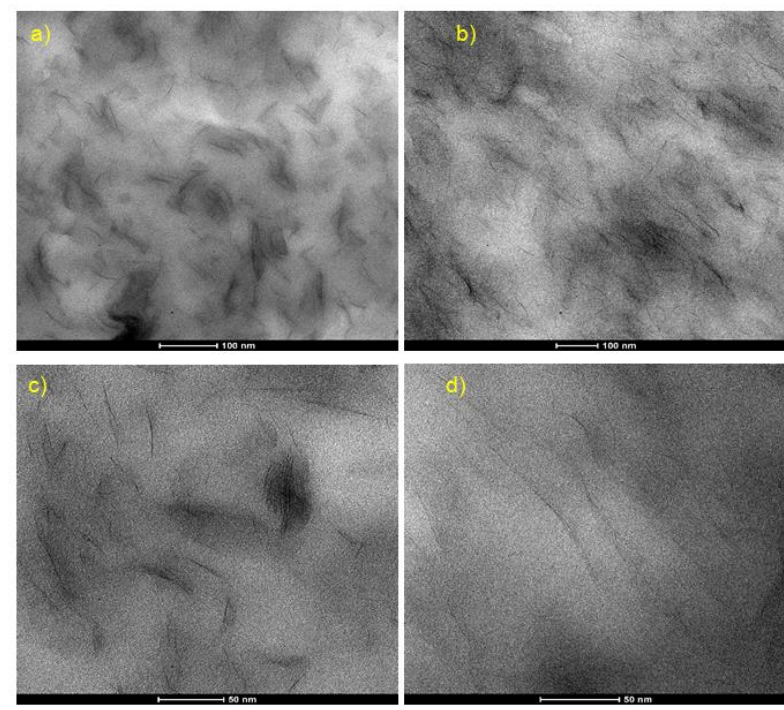

Fig. 2: TEM images of PA6/5 wt.\% C30B nanocomposites with and without chain extender: (a \& c) without Joncryl; (b \& d) 1 wt.\% Joncryl, the top and the bottom images are related to low and high images respectively.

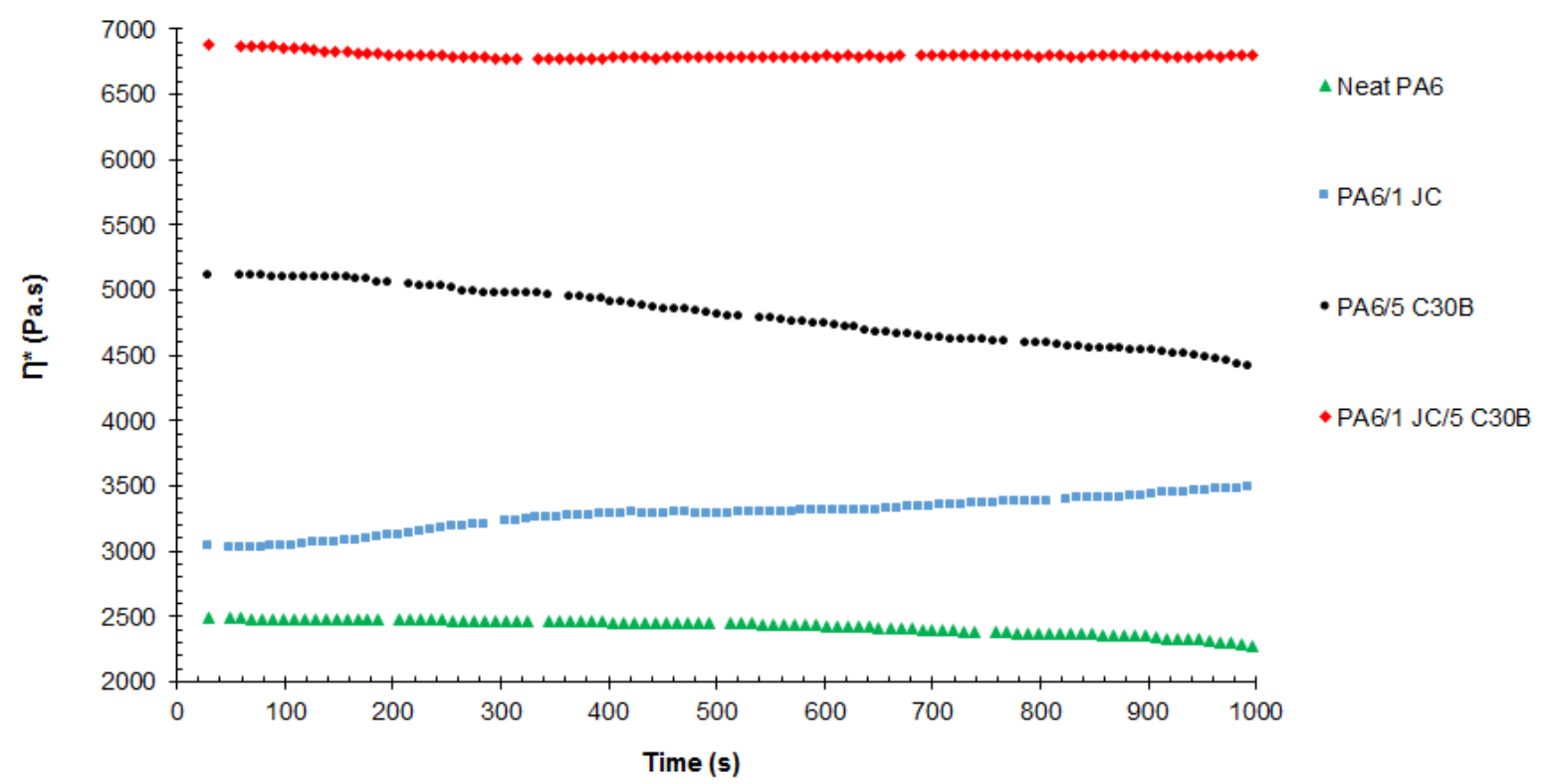

Fig. 3: Complex viscosity as a function of time for PA6 and PA6/organoclay nanocomposites with and without chain extender. 
Now for PA6/1 JC/5 C30B, the chain extended nanocomposite, comparison with the nanocomposite PA6 /5 C30B show clearly the benefit of Joncryl in controlling thermal degradation over time, the chain extended nanocomposite displaying, as shown in Fig. 3, a stable complex viscosity over time whereas there is a gradual decrease for the non-extended nanocomposite. However, when the thermal stabilities of PA6/1 JC/5 C30B and PA6/1 JC over time are compared, Joncryl effectiveness is somehow reduced by the presence of the organoclay. Such behavior of the non-extended nanocomposites can be explained by the accelerated thermal degradation effect of the organo-modifier on the clay under high temperature and shear during the rheological tests. As explained earlier, whereas in the extruder the residence time is short (ca. 1min) and probably insufficient to complete the chain extension reaction, in the rheometer the reaction can continue.

Figs. 4a,b present the complex viscosity and the storage modulus of PA6 and PA6/organoclay nanocomposites with and without chain extender as a function of frequency. It is seen from both figures that the non extended nanocomposite PA6/5 C30B shows higher viscosity and modulus than the neat PA6 (6000 Pa.s and $1500 \mathrm{~Pa}$ compared with $2600 \mathrm{~Pa}$.s and $80 \mathrm{~Pa}$ at $0.1 \mathrm{~Hz}$ ). Such increase gives confidence in the success of the experiments in achieving nanocomposites and confirms the intercalations and exfoliation of the nanoclay within the PA6 matrix observed in the TEM images of Fig. 2. This significant increase in the rheology also suggests that the incorporation of the chain extender has lead to chain branching. Accordingly, a plot of the loss angle $\left(\delta=\arctan \left(\mathrm{G}^{\prime \prime} / \mathrm{G}^{\prime}\right)\right)$ vs. frequency was used to assess this. Fig. 5 presents such data, comparing neat PA6 with PA6/1 JC and showing at $0.1 \mathrm{~Hz}$ frequency a loss angle approaching $90^{\circ}$ for the neat polymer and a lower angle, decreasing comparatively steeply for the chain extended polymer. Such behaviour is consistent with the observations made by Najafi et al. [12] and Ghanbari et al. [13]. With regard to the evidence of chain branching, it is also important to note that overdosing with Joncryl with loading larger than $1 \%$ leads to very high torques developing during extrusion, making it impossible to operate, suggesting crosslinking as observed in our previous work [15].

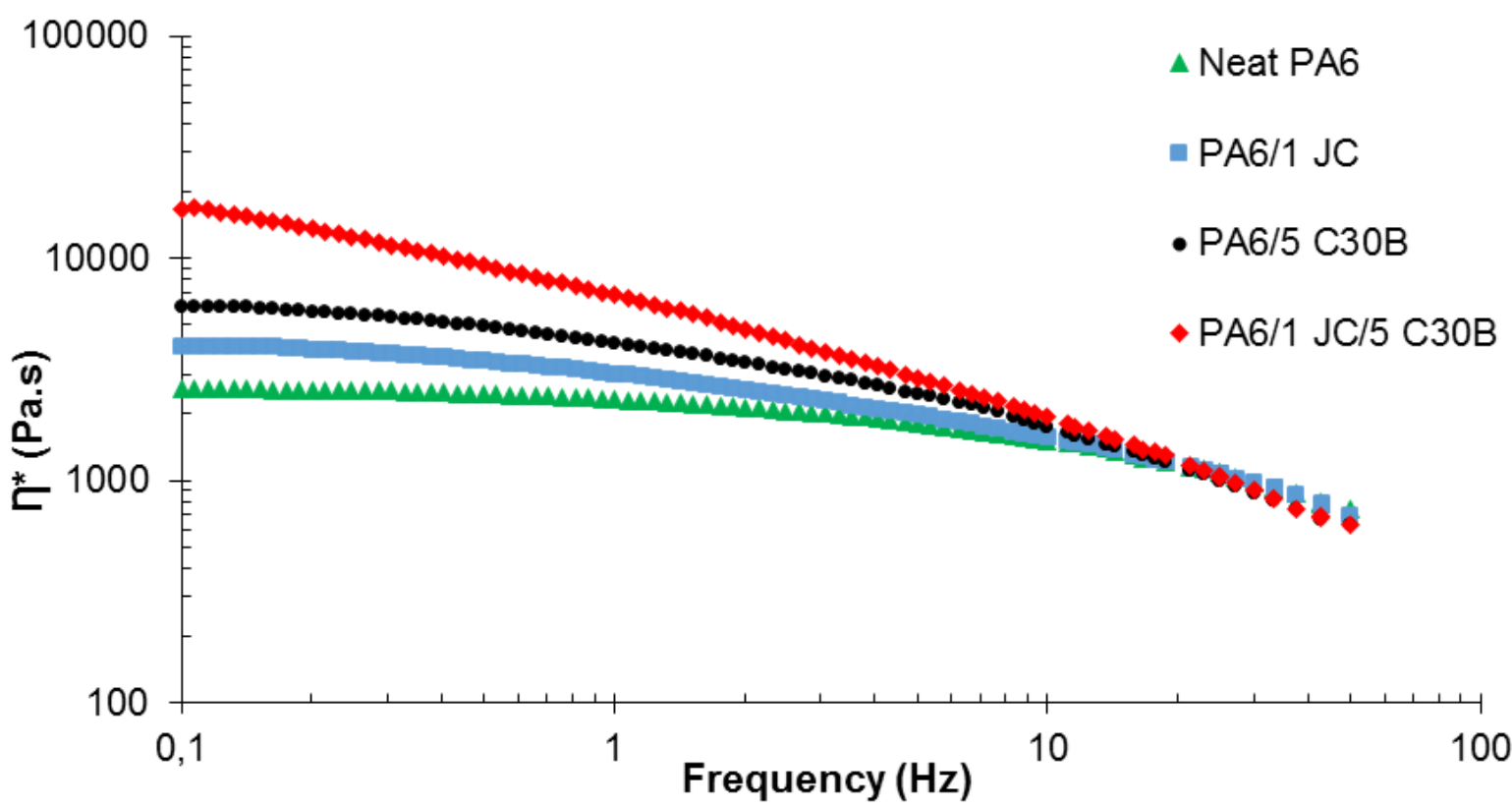

Fig. 4a: Complex viscosity as a function of frequency for PA6 and PA6/organoclay nanocomposites with and without chain extender. 


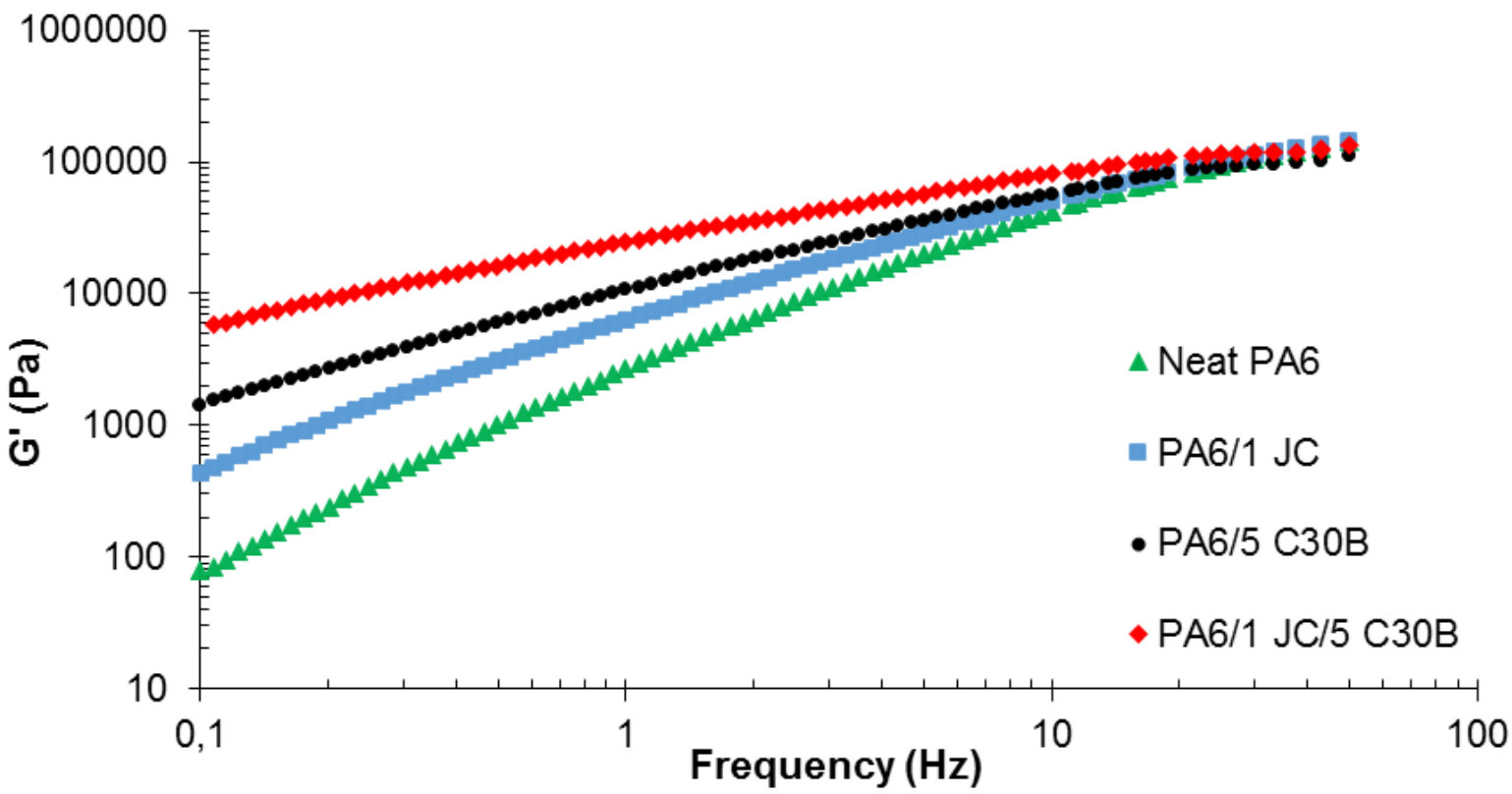

Fig. 4b: Storage modulus as a function of frequency for PA6 and PA6/organoclay nanocomposites with and without chain extender.

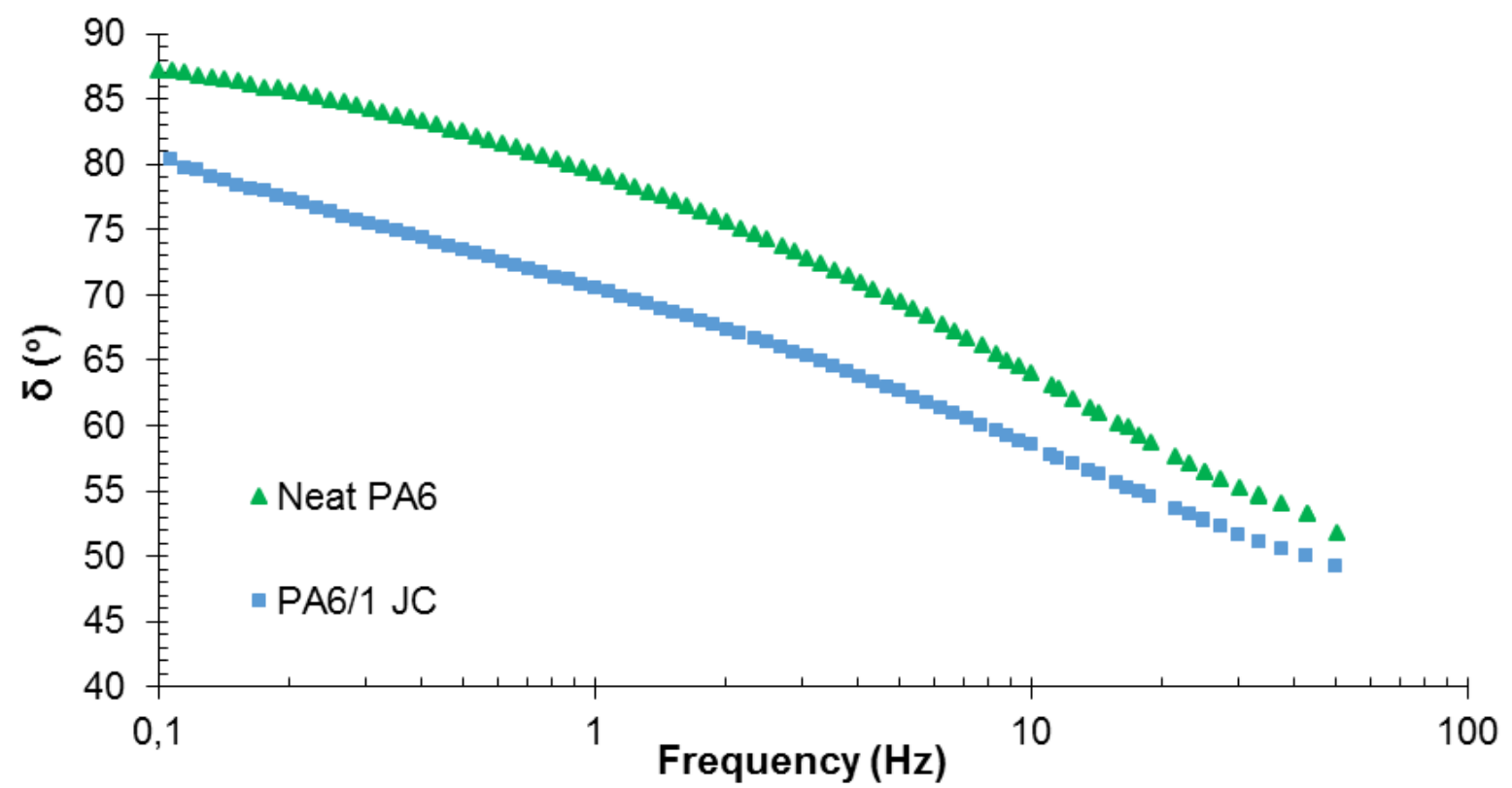

Fig. 5: Loss angle as a function of frequency for PA6 with and without chain extender.

Another interesting observation from the measured rheology (see Fig.4a) is the strong shear thinning behaviour of the chain extended nanocomposite (PA6/1 JC/5 C30B) comparatively with the non chain extended nanocomposite PA6/5 C30B. This suggests that the addition of the chain extender not only increased viscosity but, as a result of the ensuing large shear forces, also the degree of exfoliation. Following Wagener and Reisinger [24], a power-law fit $\left(\eta^{*}=\right.$ $K \omega^{n-1}$ ) to the data of Fig.4a in the low frequency range is given in Fig.6 quantifying the extent of exfoliation, showing it to be measurably large with the chain extended nanocomposite. 


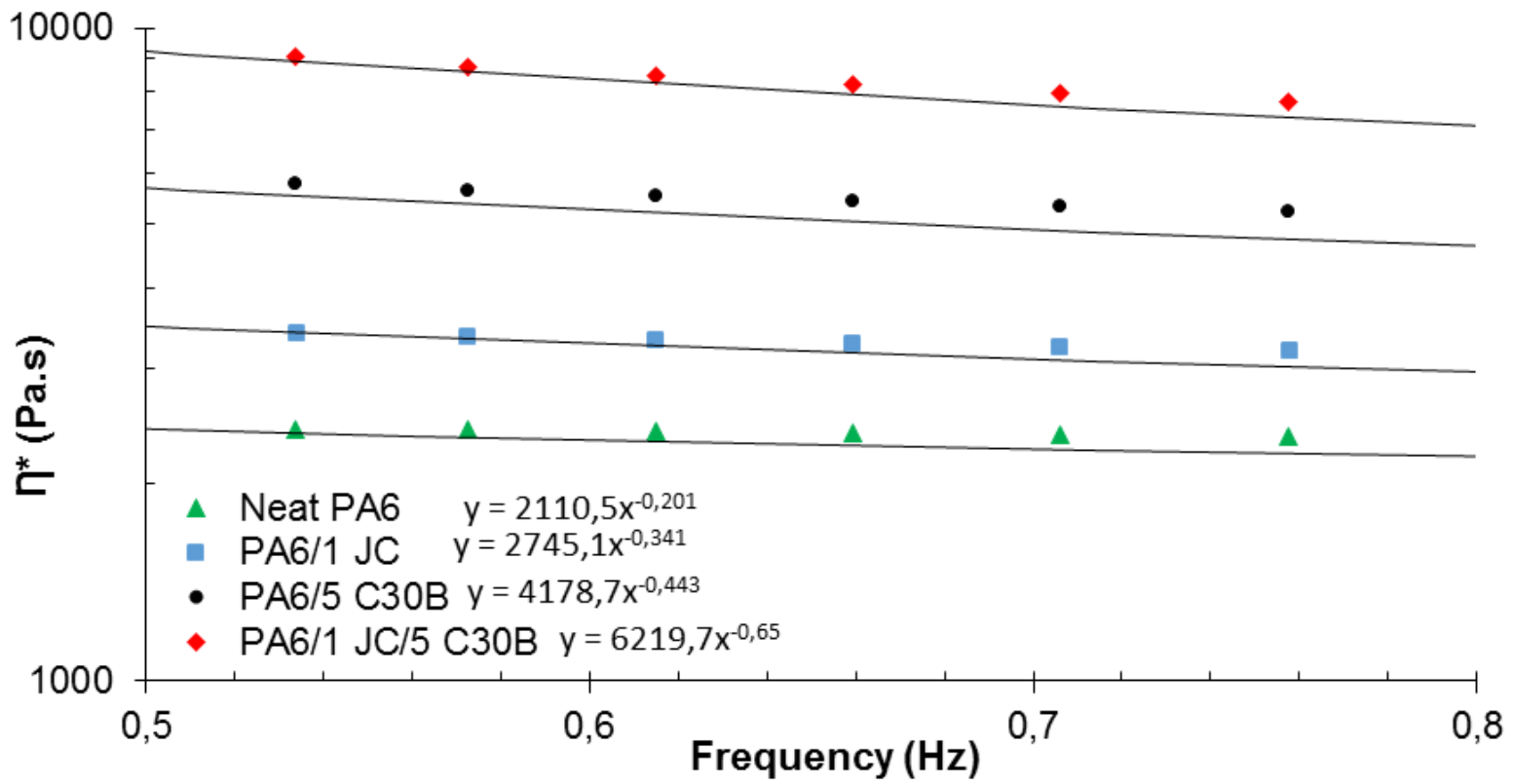

2 Fig. 6: Low frequency dependence of the complex viscosity for PA6 and PA6/organoclay.

3

4

5

6

7

8

9

10

11

\subsection{Mechanical Properties}

Here, we seek to link the morphological and rheological observations made above with the mechanical properties measured on the solids samples, presented in Table 1. The first observation is the expected reinforcing effect $[24,25]$ of the addition of the nanoclay as measured in the tensile modulus, an increase of $53 \%$ for the non extended nanocomposite compared with the neat polymer and an increase of 57\% for the extended nanocomposite compared with the neat polymer. The second observation is that the addition of the chain extender provides an extra reinforcement, a $6.3 \%$ increase in the tensile modulus in the case of the neat polymer and a $2.8 \%$ in the case of the nanocomposite. This tallies perfectly with the morphological and rheological observations made above: the organoclay enhances mechanical properties very significantly indicating a very good dispersion of the nanoclay into the polymer; the chain extender reconnects the broken chains but more effectively in the neat PA6 than in the nanocomposite.

Table 1: Tensile properties of PA6 and PA6/organoclay nanocomposites with and without chain extender.

\begin{tabular}{|l|c|c|c|}
\hline Sample & $\begin{array}{c}\text { Tensile modulus } \\
\text { (MPa) }\end{array}$ & $\begin{array}{c}\text { Yield strength } \\
\text { (MPa) }\end{array}$ & $\begin{array}{c}\text { Yield strain } \\
\text { (\%) }\end{array}$ \\
\hline Neat PA6 & $2792.4 \pm 39.9$ & $74.7 \pm 3$ & $3.3 \pm 0.3$ \\
\hline PA6/1 JC & $2969.2 \pm 65.6$ & $75.7 \pm 1.8$ & $2.9 \pm 0.1$ \\
\hline PA6/5 C30B & $4277.9 \pm 128.3$ & $77.7 \pm 1.2$ & $2.2 \pm 0.1$ \\
\hline PA6/1 JC/5 C30B & $4395.7 \pm 102.5$ & $78.2 \pm 0.7$ & $2.1 \pm 0.1$ \\
\hline
\end{tabular}

The yield stress data follows the observations concluded from the tensile modulus data: a $4.0 \%$ increase for the non extended nanocomposite compared with the neat polymer and an increase of $4.7 \%$ for the extended nanocomposite compared with the neat polymer. The 
addition of the chain extender provides extra reinforcement, a 1.3\% increase in the yield strength in the case of the neat polymer and a $0.6 \%$ in the case of the nanocomposite. We must note here that eventhough these increases are very small, they are measurable within experimental errors. As observed in other studies [26-30], an enhancement of the yield strength, even if small, is an indicator of a good filler matrix interaction, confirming the good interaction and (hydrogen) bonding between PA6 and Cloisite 30B as evidence earlier by the high degree of exfoliation. There is also the contribution of the chain branching resulting from the addition of the chain extender, as discussed earlier.

With regard to yield strain, we observe that the addition of the organoclay reduces it by about $1 / 3$, from $3.3 \%$ to $2.2 \%$ when no extender was added and from $3.3 \%$ to $2.1 \%$ in the presence of the chain extender. A comparison of the neat and chain extended PA6, showing a reduction of yield strain from $3.3 \%$ to $2.9 \%$ points to the greater effect of the addition of the organoclay. This more brittle structure with the addition of organoclay can be attributed to the presence of some undispersed clay agglomerates forming microvoids, thus triggering crack propagation throughout the matrix. As the chain extender promotes branching, its addition increases entanglement density and reduces orientation of polymer chains upon elongation, explaining the decrease in the strain. Such behaviour has been observed in other studies $[11,12,31]$.

\subsection{Thermal Properties}

The DSC thermograms of the samples are presented in Fig.7. A shoulder is observed in the melting endotherms of the samples with added chain extender and/or organoclay. This correponds to the melting of the $\gamma$ and $\alpha$ crystalline phases [32] at $209{ }^{\circ} \mathrm{C}$ and $222{ }^{\circ} \mathrm{C}$, respectively. This is a typical polymorphism feature of PA6 with the incorporation of the nanoclay promoting the formation of the $\gamma$ crystalline phase $[33,34]$. Here, the addition of the chain extender (PA6/1 JC) is showing a similar polymorphism, an interesting and new observation from this study, most probably linked to chain branching, explaining the rheological and mechanical properties discussed earlier. Interestingly also, is the higher glass transition temperature measured with PA6/1JC which can be explained by the formation of longer chains after the chain extension reaction following Fox-Flory well known equation [35] on the variation of $T_{g}$ with molecular weight:

$$
T_{g}=T_{g_{\infty}}-\frac{C}{M_{n}}
$$

where $T_{g_{\infty}}$ is the glass transition temperature of the polymer with infinite molecular weight, $\mathrm{M}_{\mathrm{n}}$ the number average molecular weight, and $\mathrm{C}$ a constant [35]. With regard to crystallinity, it is clear from Table 2 that organoclay addition enhances nucleation, spherulites growth and therefore increases crystallization of the polymer nanocomposite. Chain extension, though forming $\gamma$ crystallites as noted earlier, hinders the packing of PA6 chains to form a crystal lattice thus resulted in decreased crystallinty. Similar observations regarding the effect of chain extenders on the crystallization behavior of polymers have been reported $[11,12,36,37]$.

The data on thermal stability upon addition of the chain extender and/or clay are presented in Fig.8 in the range of temperatures corresponding to the extrusion conditions. The nanocomposites showed nearly 5\% residue confirming the organoclay content in the samples. Although marginal as a result of the range of temperatures tested, the benefit of adding the chain extender is measurable when we compare the polymer and the nanocomposite with and without the chain extender. As shown in Table 2, Joncryl improved the thermal stability of PA6 reflecting a slightly enhanced onset temperature $\left(\mathrm{T}_{\text {onset }}\right)$ due to recoupling of the degraded chain ends. The nanocomposites presented lower $\mathrm{T}_{\text {onset }}$ than the neat PA6 due to the thermal degradation of the organo-modifier in the clay. Joncryl resulted in an increased $\mathrm{T}_{\text {onset }}$ of the nanocomposites indicating a higher thermal stability of the nanocomposite. 


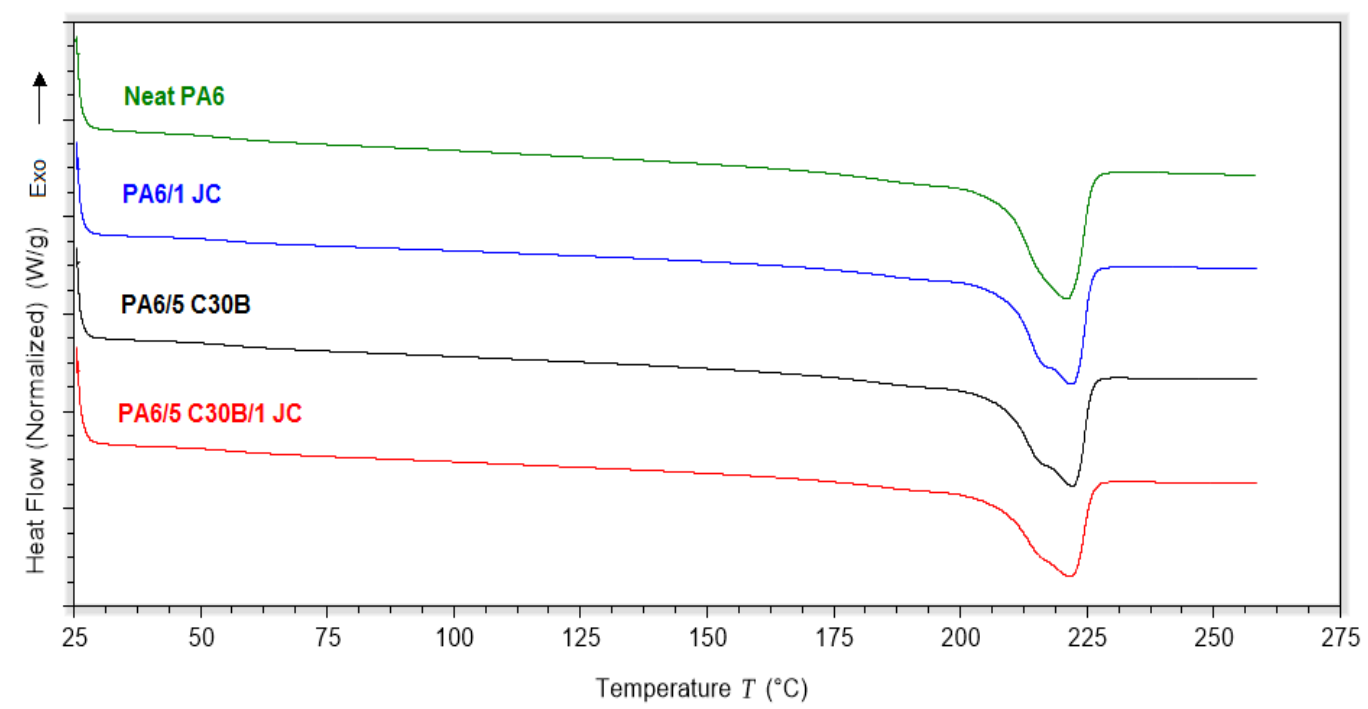

Fig. 7: DSC heating thermograms for PA6 and PA6/organoclay nanocomposites with and without chain extender.

Table 2: Thermal properties of PA6 and PA6/organoclay nanocomposites with and without chain extender.

\begin{tabular}{|l|c|c|c|c|c|}
\hline Sample & $\mathbf{T}_{\mathrm{g}}\left({ }^{\circ} \mathrm{C}\right)$ & $\mathbf{T}_{\mathrm{m}}\left({ }^{\circ} \mathrm{C}\right)$ & $\mathbf{T}_{\mathrm{c}}\left({ }^{\circ} \mathrm{C}\right)$ & $\mathbf{X}_{\mathrm{c}}(\%)$ & $\mathbf{T}_{\text {onset }}\left({ }^{\circ} \mathrm{C}\right)$ \\
\hline Neat PA6 & 53.7 & 221.1 & 188.4 & 20.2 & 389.2 \\
\hline PA6/1 JC & 55.5 & $209.1 / 222.6$ & 187.7 & 18.6 & 396.0 \\
\hline PA6/5 C30B & 54.3 & $208.8 / 222.6$ & 189.2 & 22.4 & 381.4 \\
\hline PA6/1 JC/5 C30B & 54.5 & $209.8 / 222.2$ & 184.9 & 16.6 & 385.4 \\
\hline
\end{tabular}

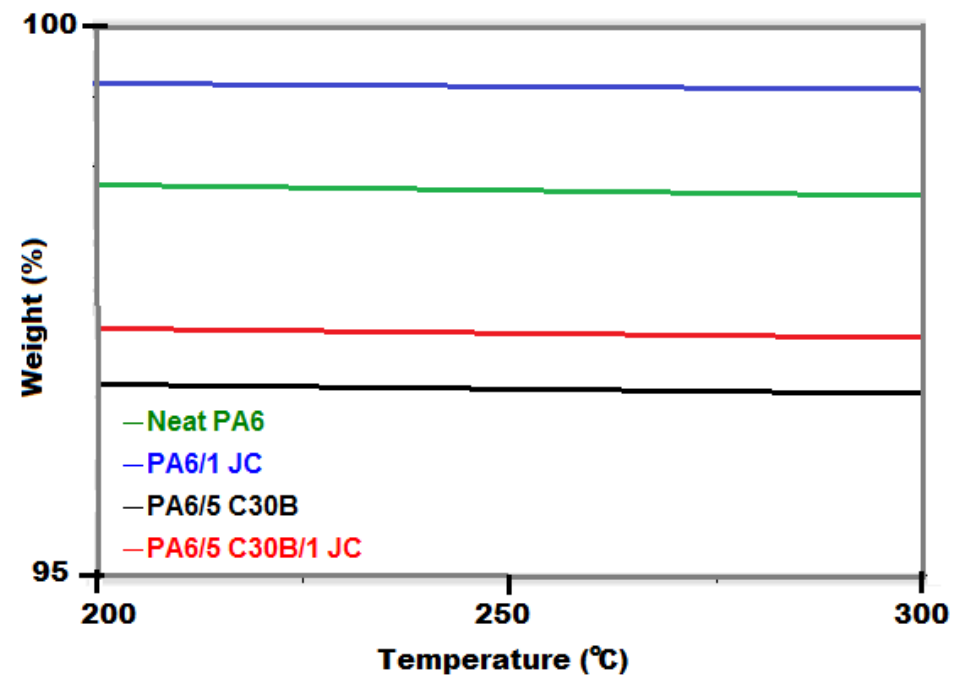

Fig. 8: TGA curves for PA6 and PA6/organoclay nanocomposites with and without chain

\subsection{FTIR Spectroscopy}

Extender.

As explained earlier, during chain extension the amide end groups of PA6 react with anhydride groups to form stable imide bonds according to the reaction illustrated in Fig. 1 [38]. 
On the basis of this reaction, FTIR analysis was performed on the neat PA6, Joncryl and PA6/Joncryl in an attempt to observe evidence of imide bonds formation. As can be seen from the spectra of Fig. 9, Joncryl exhibited anhydride characteristic peaks at 1774.22 and 1856.18 $\mathrm{cm}^{-1}$ for $\mathrm{C}=\mathrm{O}$ stretching vibrations and at 1217.85 for $\mathrm{C}-\mathrm{O}-\mathrm{C}$ stretching vibrations which are not observed in the spectra of PA-6/Joncryl. The amide and $\mathrm{C}=\mathrm{O}$ and amide and $\mathrm{C}-\mathrm{N}$ stretching vibrations appear in both the neat PA6 and PA6/Joncryl at their characteristic peaks $\sim 1632$ and $\sim 1538 \mathrm{~cm}^{-1}$ respectively but in comparatively diminished transmittance. Essentially, it is the very low Joncryl concentration added (1 wt.\%) that makes it difficult to detect changes. 9 Related studies [39-41] have shown the C-N stretching mode in imide compounds is inherently 10 IR weak and can only be seen if the concentration of anhydride species in our case is high.

11

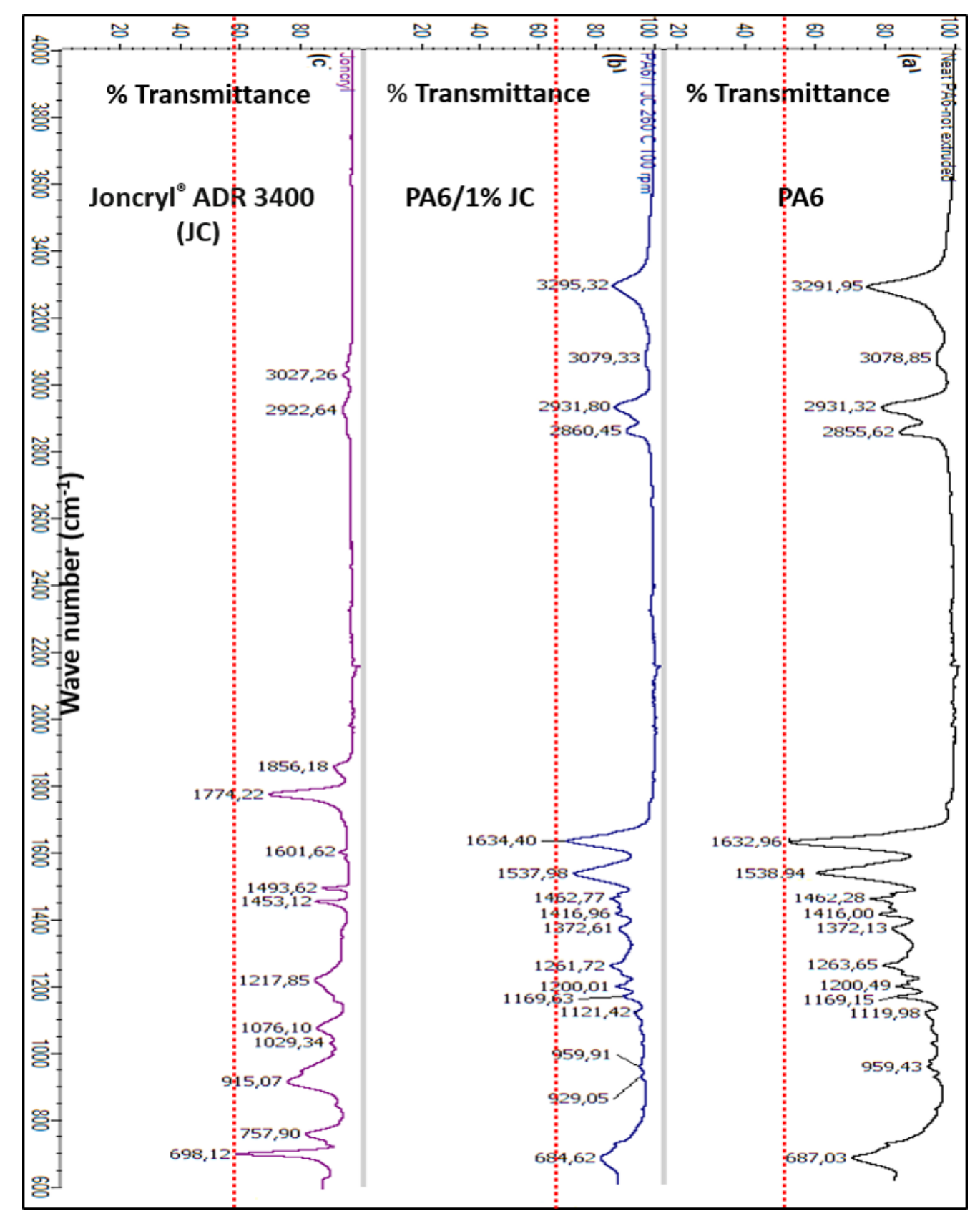

Fig. 9: FTIR spectra of PA6, Joncryl and PA6/1\% Joncryl 


\section{CONCLUSION}

A chain extender with multiple anhydride functionalities, Joncryl ${ }^{\circledR}$ ADR 3400 was used to test its potential for offseting the thermal degradation of PA6 clay nanocomposite during melt extrusion. The organoclay Cloisite 30B was found to be most appropriate to form a good nanocomposite, intercalating and exfoliating well into PA6 as evidenced from TEM morphological observations and reflected in the rheological and mechanical properties measured. A 5\% nanoclay addition more than doubled the complex viscosity $\eta^{*}$ and increased the storage modulus $G^{\prime}$ by a factor of 19 at frequency $0.1 \mathrm{~Hz}$ where the structure is at its least perturbed state rheologically. As for the tensile modulus, it increased by $53 \%$ proving the reinforcing effect of the nanoclay. Upon addition of the chain extender, only at $1 \%$, the enhancement in the rheological properties increased further, 7 times in the complex viscosity, 88 times in the storage modulus whilst the tensile modulus increased by $48 \%$, compared to the neat polymer. Chain extension with this anhydride copolymer has been effective, as predicted, the anhydride functionalities being strongly reactive with the amide end groups of the degraded PA6, reconnecting the broken chains and most probably changing the original linear structure of PA6 into a long branched structure.

An interesting and new observation in this study is the strong shear thinning behaviour in the low frequency range of the chain extended nanocomposite comparatively with the non chain extended nanocomposite. This suggests that the addition of the chain extender not only increased viscosity but, as a result of the ensuing large shear forces, also the degree exfoliation.

\section{Acknowledgements}

The authors acknowledge BASF, Germany for supplying Joncryl ${ }^{\circledR}$ ADR 3400 used in this study.

\section{References}

1. S.S. Ray, Clay Containing Polymer Nanocomposites: From Fundamentals to Real Applications, Elsevier, Oxford, (2013).

2. W. Lertwimolnun, and B. Vergnes, Polym. Eng. Sci., 46, 314 (2006).

3. V. Mittal, Synthesis Techniques for Polymer Nanocomposites, Wiley-VCH Verlag GmbH\&Co, Weinheim, (2015).

4. J.A. Loontjens, "Performance materials by a modular approach", $\mathrm{PhD}$ Thesis, Eindhoven University of Technology, (2005).

5. J. Scheirs, and T.E. Long, Modern Polyesters: Chemistry and Technology of Polyesters 6 and Copolyesters, John Wiley \& Sons, Sussex, (2003).

6. H. Li, and M.A. Huneault, J. Appl. Polym. Sci., 122, 134 (2011).

7. F. Gao, Mater. Today, 7, 11 (2004).

8. T.D. Fornes, P.J. Yoon, and D.R. Paul, Polymer, 44, 7545 (2003).

9. G.M. Russo, V. Nicolais, L. Di Maio, S. Montesano, and L. Incarnato, Polym. Degrad. Stab., 92, 1925 (2007).

10. R.D. Davis, J.W. Gilman, and D.L. VanderHart, Polym. Degrad. Stab., 79, 111 (2003).

11. N. Najafi, M.C. Heuzey, P.J. Carreau, and P.M. Adams, Polym. Degrad. Stab., 97, 554 (2012).

12. N. Najafi, M.C. Heuzey, and P.J. Carreau, Compos. Sci. Technol., 72, 608 (2012).

13. A. Ghanbari, M.C. Heuzey, P.J. Carreau, and M.T. Ton-That, Polymer, 54, 1361 (2013).

14. S.V. Levchik and E.D. Weil, Polym. Int., 48, 1 (1999)

15. B. Tuna, and H. Benkreira, Polym. Eng. Sci., 58, 1037 (2017).

16. M. Paci, S. Filippi, and P. Magagnini, Eur. Polym. J., 46, 838 (2010). 
17. O. Monticelli, Z. Musina, A. Frache, F. Bellucci,G. Camino, and S. Russo, Polym. Degrad. Stab., 92, 370 (2007).

18. S. Woo Kim, W. Ho Jo, M. Sung Lee, M. Bae Ko, and J. Young Jho, Polym. J., 34, 103 (2002).

19. M. Gomez, H. Palza, and R. Quijada, Polymers, 8, 386 (2016).

20. H. Benkreira, R. Butterfield, M. Gale and R. Patel, Plastics, Rubber and Composites: Macromolecular Engineering, 37, 74, 2008.

21. B. Tuna, "Chain extension of PA6 and PA6-organoclay nanocomposites", PhD Thesis, University of Bradford, (2016).

22. E. Logakis, C. Pandis, V. Peoglos, P. Pissis, C. Stergiou, J. Pionteck, P. Potschke, M. Micusik, and M. Omastova, J. Polym. Sci., Part B: Pol. Phys., 47, 764 (2009).

23. Q. Meng, M.C. Heuzey, and P.J. Carreau, Polym. Degrad. Stab., 97, 2010 (2012).

24. R. Wagener, and T.J.G. Reisinger, Polymer, 44, 7513 (2003).

25. M. Chan, K. Lau, T. Wong, M. Ho, and D. Hui, Compos. Part B Eng., 42, 1708 (2011).

26. S. Boran, A. Kiziltas, E.E. Kiziltas, D.J. Gardner, and T.S. Rushing, Polym. Eng. Sci., 57, 324 (2017).

27. I.Y. Phang, T. Liu, K.P. Mohamed Pramoda, L. Chen, L. Shen, S.Y. Chow, C. He, X. $\mathrm{Lu}$, and X. Hu, Polym. Int., 54, 456 (2005).

28. S. Hotta, and D.R. Paul, Polymer, 45, 7639 (2004).

29. J. Morawiec, A. Pawlak, M. Slouf, A. Galeski, E. Piorkowska, and N. Krasnikowa, Eur. Polym. J., 41, 1115 (2005).

30. A. Ranade, K. Nayak, D. Fairbrother, and N.A. D’Souza, Polymer, 46, 7323 (2005).

31. M. Tanniru, Q. Yuan, and R.D.K. Misra, Polymer, 47, 2133 (2006).

32. D. Garcia-Lopez, J.C. Fernandez Merino, J. Santaren, and J.M. Pastor, Compos. Sci. Technol., 70, 1429 (2010).

33. T.D. Fornes, and D.R. Paul, Polymer, 44, 3945 (2003).

34. S. Xie, S. Zhang, H. Liu, G. Chen, M. Feng, H. Qin, F. Wang, and F. Yang, Polymer, 46, 5417 (2005).

35. T.G. Fox, and P.J. Flory, J. Appl. Phys., 21, 581 (1950).

36. B. Tuna, and H. Benkreira, Polym. Eng. Sci., 59, E25 (2018).

37. C. Lu, R. Ye, Y. Yang, X. Ren, and X. Cai, J. Macromol Sci. Phys., 50, 350 (2015).

38. S. Thomas and G. Groeninck, Polymer, 40, 5799 (1999).

39. C.B. Chapman and L. Valentine, J. Polym. Sci, 34, 319 (1959).

40. F. Chang and Y.Hwu, Polym. Eng. Sci., 31, 1509 (1991).

41. A. K. Saini, C. M. Carlin, H. H. Patterson, J. Polym. Sci., 31, 2751 (1993).

\section{FIGURES AND TABLES CAPTIONS}

Fig. 1: Reaction mechanism and chemical structure of Joncryl 3400. R1-R6 are H, CH 3, a higher alkyl group or combinations of them; R7 is an alkyl group and $\mathrm{x}, \mathrm{y}$ and $\mathrm{z}$ are all between 1 and 20.

Fig. 2: TEM images of PA6/5 wt.\% C30B nanocomposites with and without chain extender: (a \& c) without Joncryl; (b \& d) 1 wt.\% Joncryl, the top and the bottom images are related to low and high images respectively.

Fig. 3: Complex viscosity as a function of time for PA6 and PA6/organoclay nanocomposites with and without chain extender.

Fig. 4: a) Complex viscosity and b) storage modulus as a function of frequency for PA6 and 
1 PA6/organoclay nanocomposites with and without chain extender.

Fig. 5: Loss angle as a function of frequency for PA6 with and without chain extender.

Fig. 6: Low frequency dependence of the complex viscosity for PA6 and PA6/organoclay nanocomposites with and without chain extender with power law fitting equations.

Fig. 7: DSC heating thermograms for PA6 and PA6/organoclay nanocomposites with and without chain extender.

Fig. 8: TGA curves for PA6 and PA6/organoclay nanocomposites with and without chain extender.

Fig. 9: FTIR spectra of PA6, Joncryl and PA6/1\% Joncryl.

Table 1: Tensile properties of PA6 and PA6/Organoclay nanocomposites with and without chain extender.

Table 2: Thermal properties of PA6 and PA6/Organoclay nanocomposites with and without chain extender. 